conclusions drawn from the study but will make it difficult to formulate recommendations for parents. The tog values quoted on duvets and the like are not scaled in this way. Parents choosing a commercial 9 tog quilt combined with a small amount of clothing might assume that they would be covering the baby with more than 10 togs and exposing it to danger, but in fact by the definition used in the paper they would not be as the scaled tog value would be only 8 or 9 . The figures used in recommendations should accord with the data provided by manufacturers of bedding.

Like many other authors of retrospective studies of sudden infant deaths Dr Fleming and colleagues have overstated the importance of their findings and confused dubious statistical correlations with risk, which can be justifiably alluded to only when a true causal relation is shown. If thermal stress is a factor in sudden infant death then the nature of its action can only be guessed at. Experience has shown that in this sensitive subject guesswork and hunches may have propaganda value but can cause parents much distress.

Undoubtedly, research is needed to discover whether thermoregulation may be relevant to sudden infant death, but we regret that the scientific community was not left to evaluate the risks thoroughly before parents were alarmed by press reports and provoked into changes in behaviour that are not yet proved to be necessary and could carry risks of their own.

University of Leicester, Leicester LE2 7LX

$S$ A PETERSEN

I Fleming JP, Gilbert R, Azaz Y, et al. Interaction between bedding and sleeping position in the sudden infant death syndrome: a population based case-control study. $\mathrm{Br} \mathrm{Med} f$ 1990;301:85-9. (14 July.)

SIR, - The two articles ${ }^{12}$ and a letter ${ }^{3}$ from the group at Bristol and Bath may do much to change our thinking on the sudden infant death syndrome. The high rate in the four districts has not raised the postneonatal mortality, which for the same period was only $4 \cdot 2 / 1000$ live births ${ }^{4}$ just $0 \cdot 1$ above that for England and Wales. The high rate must therefore have been due to the authors' refusal to accept minor changes in the respiratory system as a cause of death. Thus even when there were equivocal findings the baby was still classified as dying of the sudden infant death syndrome. ${ }^{5}$

In their letter they give the incidence of the syndrome in the four districts as $2 \cdot 83 / 1000$ live births, which is higher than that for England and Wales. The Office of Population Censuses and Surveys, however, publishes two sets of figures on the subject. The first is the one they quote from, which deals with sudden deaths (any mention on the death certificate) ${ }^{6}$ Later, after further scrutiny, figures for sudden deaths (sole cause) are published. ${ }^{7}$ All those deaths ascribed to alternative causes are listed under them so that only deaths with no other cause are ascribed to the sudden infant death syndrome. ${ }^{6}$ The transfer is made on the general basis of a more specific diagnosis taking precedence over a less specific one. The figures are presented on a national and regional basis but not

yet on a district one. In 1979 some $28 \%$ of all sudden deaths were transferred to alternative diagnoses, but by 1985 only $10 \%$ were transferred. So even on certification fewer causes of deaths are diagnosed equivocally. The figures for the sudden infant death syndrome (sole cause) may be more reliable than has been thought.

Some of the deaths transferred during the scrutiny have definite causes such as purulent meningitis and they must remain in their correct diagnostic category. Yet at the end of the scrutiny the cause of death of some babies is still equivocal. To get the higher and more accurate figure it will be necessary to add these deaths from equivocal causes to those solely caused by the sudden infant death syndrome as they have done in Avon.

The table shows what happens when the figures for South Western region ${ }^{47}$ are treated in this way. Over the seven years the sole cause rate was $2 \cdot 19 / 1000$ but by adding the equivocal causes it rises to $2 \cdot 67$. The yearly combined rates were about this figure until 1984-5. The fall in these two years is the same as the national fall that occurred then and has never been explained. So the figure of 2.6 for this region in 1987 is quite in keeping with the overall rise in rates in 1986, which has since been reversed.

Dr Peter J Fleming and colleagues suggest that overbedding may result in hyperpyrexia, which may be the cause of death in some cases. ${ }^{2}$ As a result parents will probably be more watchful in this respect and if the theory is correct then in some districts at least the sudden infant death rate will fall. It is important to gather as much information as possible at district level so that the trend can be accurately monitored. All that is required is to add the deaths from equivocal causes to those from the sudden infant death syndrome and relate them to the total live births. This has an additional advantage in that it discounts the whims of the pathologist.

R R GORDON

Halstead, Essex CO9 1SF

1 Gilbert RE, Fleming PJ, Azaz Y, Rudd PT. Signs of illness preceding sudden unexpected death in infants. $\mathrm{Br} \mathrm{Med} \mathcal{F}$ 1990;300:1237-9. (12 May.)

2 Fleming PJ, Gilbert R, Azaz Y, et al. Interaction between bedding and sleeping position in the sudden infant death syndrome: a population based case-control study. $\mathrm{Br} \mathrm{Med} f$ 1990;301:85-9. (14 July.)

3 Gilbert R, Fleming PJ, Berry JEM, Rudd P. Signs of illness preceding sudden infant death. Br Med $\mathcal{F}$ 1990;301:45-6. (7 July.)

4 Office of Population Censuses and Surveys. Infant and perinatal mortality 1986-7. London: HMSO, 1987. (DH3 87/4 and 88/2.) 5 Emery JL. Is sudden infant death syndrome a diagnosis? BrMed f 1989;299:1240.

6 Office of Population Censuses and Surveys. Sudden infant deaths 1985-7. London: HMSO, 1988. (DH3 88/3.)

7 Office of Population Censuses and Surveys. Mortality statistics. childhood 1979-85. London: HMSO, 1987. (DH3 No 19.)

SIR,-In this study by Dr Peter J Fleming and colleagues the difference in weight between the case and control groups was $660 \mathrm{~g} .{ }^{1}$ As the infants were matched for age and the authors stated that there had been no appreciable weight loss before death in the group who had died this would imply that the birth weight of the two groups differed. Preterm birth increases the risk of sudden infant

Numbers and causes of sudden infant deaths in South Western region 1979-85'

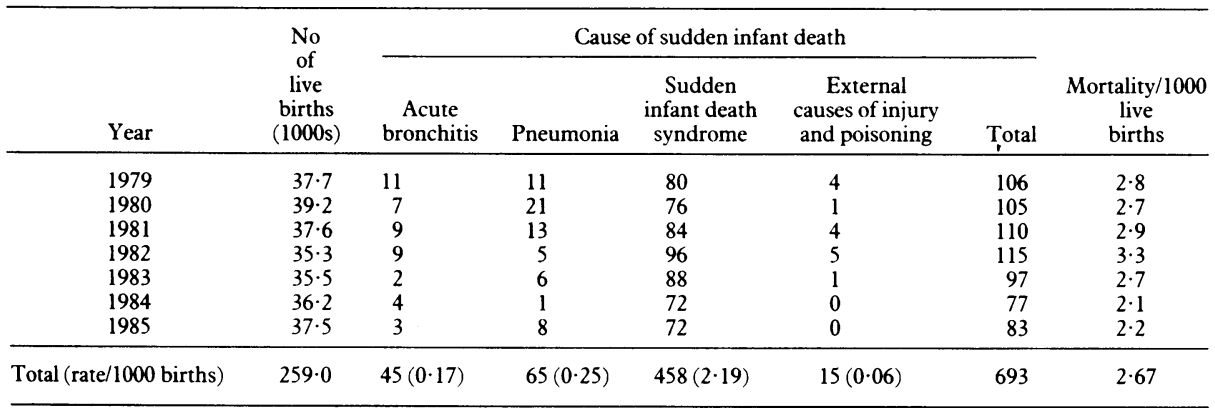

death, and in neonatal units it is often policy to place infants prone. Preterm birth is thus a potential confounder of the relation between position and sudden infant death and should be adjusted for. Perhaps preterm birth could also confound the association with overwrapping as parents might be more afraid that their infant will "catch cold" and therefore add extra clothing. The authors did not state if confounding by preterm birth had been tested for.

Our final comment concerns the authors' advice concerning the sleeping position of infants. Undoubtedly, the prone position is preferable for babies with pathological gastro-oesophageal reflux. We would disagree, however, with the recommendation that all preterm infants should be placed prone. The prone position has been shown to have advantages for preterm infants during periods of respiratory distress, although this is not unequivocal, but there would be little reason to adopt this position after the respiratory problems are over. ${ }^{2}$ Preterm infants are at increased risk of sudden infant death; to accustom them to a position other than prone therefore seems especially called for. There is little evidence that the prone position is advantageous for term infants or preterm infants past the neonatal stage. We studied infants aged 2 to 11 months and found that sleeping posture was not relevant to arterial oxygen saturation in quiet sleep for healthy infants and infants with moderately severe lower respiratory tract infection. ${ }^{3}$ For infants with moderately severe lower respiratory tract infection arterial oxygen saturation was greater in the prone position, but the difference was not such that it was likely to be clinically relevant.

ADELE C ENGLEBERTS GUUS A DE JONGE

Free University Hospital,

PO Box 7057, 1007 MB Amsterdam,

The Netherlands

1 Fleming JP, Gilbert R, Azaz Y, et al. Interaction between bedding and sleeping position in the sudden infant death syndrome: a population based case-control study. Br Med $\mathcal{f}$ 1990;301:85-9. (14 July.)

2 Levene S, McKenzie SA. Transcutaneous oxygen saturation in sleeping infants: prone and supine. Arch Dis Child 1990;65 524-6.

3 Engelberts AC, de Jonge GA. Choice of sleeping position for infants: possible association with cot death. Arch Dis Child 1990;65:462-7

SIR, - Dr Peter J Fleming and colleagues greatly underplay their main finding.' Sleeping prone had a large significant effect on the risk of death, confirming other recent evidence, ${ }^{23}$ but the authors concentrate their discussion on the thermal resistance of bedding, which carried an increased risk of only $1 \cdot 14$ per tog above 8 togs, only just significant.

There is, however, an underlying mechanism to link their findings - namely, state of arousal in sleep. Compared with those on their backs, prone babies spend more time in both active ${ }^{+}$and quiet ${ }^{5}$ sleep and move their bodies and open their eyes less ${ }^{7}$; the accompanying medullary arousal changes are reflected in the electroencephalogram. ${ }^{8}$ Apnoea has been implicated as the agonal event in sudden infant death, ${ }^{9}$ which rarely occurs when an infant is alert and responding. Prolonged apnoeic spells are much commoner during active sleep in both premature $^{510}$ and term babies," although when respiratory infection coexists there is evidence that they are commoner in quiet sleep. ${ }^{12}$ Temperature variations may also act by altering sleep and arousal states and the control of breathing ${ }^{13}$ but have a weaker effect. Thus placing babies prone or overheating them may predispose to fatal apnoea.

STEPHEN SCOTT

Institute of Psychiatry, $\mid$ London SE5 8AF

1 Fleming PJ, Gilbert R, Azaz Y. Interaction between bedding and sleeping position in the sudden infant death syndrome. and sleeping position in the sudden in

2 de Jonge GA, Engelberts AC, Koomen-Liefting AJM, Kostense 
PJ. Cot death and prone sleeping position in the Netherlands. Br.Med f 1989;298:722.

3 Beal S. Sleeping position and SIDS. Lancet 1988;ii:512.

+ Brackbill Y, Douthitt TC, West H. Psychophysiologic effects in the neonate of prone versus supine placement. $\mathcal{F}$ Pediatr $1973 ; 82: 82-4$

5 Gabriel $M$, Albani $M$, Schulte FJ. Apneic spells and sleep states in preterm infants. Pediatrics 1977;60:418-25.

6 Masterson J, Zucker C, Schulze K. Prone and supine position ing effects on energy expenditure and behaviour of low birth weight neonates. Pediatrics 1987;80:689-92.

7 Scott S, Lucas P, Cole T, Richards M. Weight gain and movement patterns of very low birthweight babies nursed on lambswool. Lancet 1983;ii: 1014-6.

8 Prechtl HFR. Polygraphic studies of the full-term newborn. London: Heinemann, 1968:1-40. (Clinics in Developmental Medicine No 27.)

9 Steinschneider A. Prolonged apnea and the sudden infant death syndrome: clinical and laboratory observations. Pediatrics 1972;50:646-54

10 Martin RJ, Herrell N, Rubin D, Fanaroff A. Effects of supine and prone positions on arterial oxygen tension in the preterm infant. Pediatrics 1979;63:528-31.

11 Hoppenbrouwers T, Hodgman J, Harper RM, Hofman E, Sterman MB, McGinty DJ. Polygraphic studies of normal infants during the first six months of life. 3. Incidence of apnea and periodic breathing. Pediatrics 1977;60:418-25.

12 Guilleminault C, Peraita R, Souquet M, Dement WC. Apneas during sleep in infants: possible relationship with sudden infant death syndrome. Science 1975;190:677-9.

13 Azaz Y, Fleming PJ, Levine MR, McCabe R. The relationship between environmental temperature, metabolic rate and sleep state in infants from birth to two months. Early Hum Dev 1989;18:293.

AUTHORS' REPLY, - In response to Dr Southall and colleagues and Drs Wailoo and Petersen the information from the bereaved families was collected directly by one of the authors, usually within 3-4 hours after the infants' death. Details of clothing, bedding, and sleeping were collected as part of a standard structured history but were not given prominence because our primary objective was bereavement counselling. For most families this was the first time that the history was taken, preceding contact with the police. Postmortem hypostatic staining was noted, corroborating the parents' description of sleeping position. Parents were asked whether their babies had been put down to sleep on their backs, fronts, or sides and, if the baby had died, whether this was the same position as that in which the baby had been found. Though there may be some ambiguity in defining the side position, there can be none in distinguishing prone from supine.

Families were too shocked to rationalise or selectively recall information, but, as a bereaved parent said, "truth is not a casualty when grief is the battleground." Collecting information so soon after the death from index and control parents and close matching for age and neighbourhood of control infants were important strengths of our study.

Drs Wailoo and Petersen ask whether the results would have been different if some of the infants who died when on their sides or supine had been more heavily wrapped. As sleeping position and tog values were shown to be independent variables it is unlikely that any difference would have been found. The median tog value for the five who died sleeping supine or on their sides was 10.3 (range 3 $111 \cdot 2)$ against $6.9(5 \cdot 4-13 \cdot 2)$ for their matched controls.

Drs Wailoo and Petersen misrepresent the concept of epidemiological risk assessment. ${ }^{2}$ Our epidemiological study found an important association between identified factors and increased risk of an adverse event. We used risk ratios at the request of the $B M \mathcal{F}$.

We use a scaling factor for tog values of bedding to account for the effect of bedding completely covering the head as the head is such an importan site of heat loss. Although we almost certainly underestimated the effects of covering the head, the approach suggested by Drs Wailoo and Petersen would not identify such effects. We agree that the tog values in our paper for bedding (but not for clothing) should be multiplied by 1.25 to relate them to the tog value marked on a duvet, but this adjustment would be incorrect if the bedding covered the baby's head partially or completely.

We have already answered some of Dr Gordon's points. ${ }^{3}$ Although the postneonatal mortality in the South Western region was not significantly above the national average for 1987 , it was higher for $1988(4 \cdot 7 v 4 \cdot 1)$, the only complete calendar year included in our recent papers. For 1988 the postneonatal mortality in the three Avon districts was $5 \cdot 0$, with a rate of sudden infant death of $3 \cdot 7$. Thus the higher rate is reflected in higher postneonatal mortalities in both the region as a whole and Avon.

In response to Drs Engelberts and de Jonge we give details of preterm and low birthweight infants studied (table). There was a slight excess of babies of short gestation among those who died, and four of them had been admitted to a special care baby unit compared with three of the control infants.

Number (percentage) of infants studied who were born before term or with low birth weight

$<35$ Weeks $35-36$ Weeks Weight $<2500 \mathrm{~g}$

$\begin{array}{llll}\begin{array}{l}\text { Infants who died } \\ (n=67)\end{array} & 3(4) & 4(6) & 3(4) \\ \begin{array}{l}\text { Control infants } \\ (n=134)\end{array} & 1(1) & 3(2) & 5(4)\end{array}$

There was no difference in sleeping position or tog value between those infants born early or of low birth weight and the others in their respective groups. Drs Engelbert and de Jonge ask if there might be another mechanism whereby prone position had effects. One possible mechanism (arousal) is suggested by Dr Scott.

Finally, should we advise parents to change from "traditional" practices? The fairly recent widespread use of the prone position for nursing infants in Britain is based on results from studies of sick preterm infants. There is no evidence that the prone position benefits infants born at term, and at least nine controlled studies have shown an increased risk of sudden infant death among infants nursed prone. ${ }^{4}$ We have been careful to emphasise the importance of parents checking whether their babies feel hot or cold and adjusting bedding accordingly. This is not different from standard teaching apart from recognising that overwrapping as well as underwrapping may be undesirable.

We also regret the distress that irresponsible reporting by the mass media may have caused Most of the comments that we have had from bereaved parents argue that careful examination of factors that may be important in the sudden infan death syndrome should continue, even if some of the results may be uncomfortable.

P J FLEMING

P J BERRY

RUTH GILBERT

Bristol Maternity Hospital

Bristol BS2 8EG

Bath Unit for Research into Paediatrics

Bath BA1 3NG

P RUDD

Institute of Child Health,

Bristol BS2 8BJ

Royal United Hospital,

Bath BAl 3NS

1 Williams T, Williams G. Guilt feelings about "cot death." The Times 1990 Aug 7:11.

2 Rose G, Barker DJP. Epidemiology for the uninitiated. London: British Medical fournal, 1986:54-5.

3 Gilbert R, Fleming PJ, Berry PJ, Rudd PT. Signs of illness preceding sudden unexpected death in infants. Br Med $\mathcal{J}$ 1990;301:45-6. (6 July.)

4 Beal S. Sleeping position and SIDS. Lancet 1988;ii:512.

SIR, - The study by Dr Peter J Fleming and colleagues is based on the recall of the parents ${ }^{1}$; such data are subject to recall bias.
Parents tend to recall whatever conforms with the norm of their social group, particularly if they feel somewhat defensive about possible neglect. Consequently, estimates of risk factors for a specific sleep position based on recall will be biased upwards for that culture's social norm. In Avon in $1990,59 \%$ of the controls had been placed in the prone position and the risk for sudden infant death was increased (a simple relative risk of 9.5) - an astonishing $93 \%$ of parents of infants who had died recalled that they had placed the babies in the prone position before death.

In Northern Ireland in 1967 Froggatt also found a significant difference between the usual sleeping position of infants who had died and that of controls based on recall, but only $6 \%$ of the mothers placed their infants in the prone position. ${ }^{2}$ The preferred position was on the side, reported for $59 \%$ of the control infants and $76 \%$ of those who died, resulting in a relative risk for sudden infant death of $2 \cdot 3$ due to the socially accepted position. In a society in which the supine position is the norm, such as Hong Kong, ${ }^{3}$ we predict that an increased relative risk would be found for cot death in that position.

As far as overheating is concerned, there is an important difference between actual thermal injury and the effect of ambient temperature on breathing. Even ambient temperatures in the thermoneutral zone as low as $32^{\circ} \mathrm{C}$ are conducive to the development of apnoea in infants otherwise prone to apnoea, such as premature babies ${ }^{+}$and infants with prolonged apnoea. ${ }^{5}$ Again, however, cultural bias is likely to affect recall. In our experience parents are more concerned about hypothermia than hyperthermia, and the resulting recall will be tilted towards overdressing.

These considerations suggest to us that sleeping position and thermal insulation are not important contributors to sudden infant death.

WARREN G GUNTHEROTH PHILIP S SPIERS

University of Washington School of Medicine,

Seattle,

Washington,

98195 United States

1 Fleming PJ, Gilbert R, Azaz Y, et al. Interaction between bedding and sleeping position in the sudden infant death syndrome: a population based case-control study. Br Med $\mathcal{J}$ 1990;301:85-9. (14 July.)

2 Froggatt $P$. Epidemiological aspects of the Northern Ireland study. In: Bergman AB, Beckwith JB, Ray CG, eds. Sudden study. In: Bergman AB, Beckwith JB, Ray CG, eds. Sudden
infant death syndrome. Washington: University of Washington infant death syndrom, $1970: 40$.

3 Davies DP. Cot death in Hong Kong: a rare problem? Lancet 1985;ii:1346-9.

4 Daily WJR, Klaus M, Meyer HPB. Apnea in premature infants: monitoring incidence, heart rate changes, and an effect of environmental temperature. Pediatrics 1969;43:510-8.

5 Steinschneider A, Weinstein S. Sleep respiratory instability in term neonates under hyperthermic conditions: age, sex, type of feeding, and rapid eye movements. Pediatr Res 1983;17:35-41.

\section{Bleeding time in patients with hepatic cirrhosis}

SIR,-Dr M Greaves and colleagues correctly state that bleeding time has not so far been shown to be predictive of bleeding risk inviver disease. ' Neither are prothrombin time and platelet count predictive, however, and these are used routinely to decide the safety of a percutaneous liver biopsy.

We identified a subgroup of patients whose prothrombin times and platelet counts were in the safe range for standard liver biopsy but who had prolonged bleeding times; they all had severe liver disease. $^{2}$ We suggest that bleeding time, as an index of primary haemostasis, is measured in this group of patients as we believe that it would be foolhardy to perform a standard liver biopsy if bleeding time is prolonged. A percutaneous plugged or transjugular liver biopsy could be performed instead. We cited one group with 